\title{
The Process of Liberalization of Electricity Market in Albania
}

\author{
Helga Zogolli \\ Univeristy Europian of Tirana , Albania \\ Economic, Management
}

\begin{abstract}
The motivation for electricity liberalization differs slightly between countries; however most of the countries share common ideological and political reasons regarding disaffection with the vertically integrated monopoly model of the past and a strong belief that the success of liberalization in other industries can be repeated for the electricity industry. The introduction of competition in the electricity industry has been justified by the perceived benefits of introducing market forces in an industry previously viewed as a natural monopoly with substantial vertical economies. Therefore the motivation behind electricity liberalization is to promote in the long run efficiency gains, to stimulate technical innovation and to lead to efficient investment.First the project is reviewing from the literature, the available information on market power monitoring in electricity markets. There are briefly explained definitions, strategies, indices and methods of mitigating market power as well as the several methods of detecting market power used from market monitors/regulators. After, the general features of the electricity industry are presented briefly as background for the analysis. The main aspects of the liberalization process of this industry and the role it has played in the creation of PX-s is described.
\end{abstract}

Keywords :Market, Marketplace or organized market, Bilateral markets or Over The Counter (OTC), Spot market.

\section{1. Electricity market liberalisation}

\section{1-1 Objective and questions}

In Europe, very little attention has been paid to the role of these new marketplaces and to the issue of market design in general. Hence the main purpose of this work is to analyze how these marketplaces facilitate the trading of electricity and the role they can play in the construction of a pan-European competitive electricity market. Since the development of these marketplaces is a very recent phenomenon almost no academic work has been done on this topic in Europe. However, countries like the US, the UK and the Nordic Countries, which started the liberalization of their electricity industry at the beginning of the nineteen nineties, have greater experience with market organization.

An analysis of PX requires taking into account the "double-duality" of such institutions. First, PX-s are both a market and an institution. As a market they facilitate the trading of electricity and determine an equilibrium price. As an institution PX-s have their own objectives and constraints, and play a role in the market design of the overall electricity market. Second, the relationship between electricity PX-s and liberalization is not linear or one way: liberalization encourages the birth of such marketplaces but marketplaces are not only the results of, they are also a driving force of the liberalization process.

In spite of the clear objective and reasons for liberalizing electricity markets, many fundamental problems remain. The first results of liberalization have shown the difficulty of implementing competition in an industry previously organized as a monopoly. In the US, the meltdown of the electricity market in California has showed the risk of restructuring markets. The UK pool which was long cited as an example of restructuring was declared a failure and all of its market rules have recently been replaced. These initial problems do not prove that liberalization is doomed but show that accurate design of the market is a fundamental issue.

The study of electricity PX-s is at the heart of economics theory and especially of industrial economics and the main purpose is: What is the most efficient industrial organization? This is divided in two categories. The first deals with theoretical aspects of market functioning and market design with respect to the liberalization of the electricity industry and the emergence of PX-s. The second category of questions looks at PX-s as organized markets where supply and demand meet. 
The focus of this project will be in the economic theory models of market functioning and their application to electricity markets. Another focus will be the electricity Market Monitoring and Practice. It was not the aim of the project to examine or to evaluate the various remedies for reducing market power. However, it is useful to have some idea of the types of market mitigation methods that may be implemented by a market monitoring or regulatory authority in order to determine what the market detection techniques are more likely to be useful for this purpose.

Establishment of a PX will create new possibilities for increased trade. Therefore, in our project, we have studied and analyzed, as an example, the development of the regional electricity trading market in South East Europe (SEE). Here we have been is concentrated within the following 3 objectives:

\section{Determination of level of interest for regional trade platform}

The first objective is to determine the level of interest among stakeholders (TSOs, Ministries, Regulators, and Traders) in participating in regional trading platforms in SEE.

\section{Benchmarking of trade platform initiatives}

The second objective is to identify the most appropriate and effective platform with which to establish confidence in the regional marketplace and to accomplish the goal of increasing trade in the region through a uniform and transparent process. In doing so, we have reviewed and benchmarked the current initiatives for regional trading platforms. Currently, there are proposals from Borzen in Slovenia and OPCOM in Romania to take on the task of setting up regional trading platforms.

\section{Bank's potential role}

The third objective is to provide recommendations on what role the Banks may have in this regional trading process, and also to look at what level of capital may be required.

\section{Methodology}

The methodology, used in this project, is the description of the background theories and how they have been applied to electricity markets, as well as their strengths and limitations when used as a basis for analyzing power exchanges.

An overview of the alternative market models in economic theory is given. Reference models of perfect competition and monopoly will be analyzed, and then oligopoly models will be examined. It will be defined the fundamentals of electricity markets, i.e. supply and demand, followed by the discussion of how models can be using economic models to analyze electricity power exchanges.

Market power assessment monitoring can be performed ex-ante and ex-post, and it is based on empirical data and numerical simulations, and the purpose of the assessment can involve any of the following:

- To detect and prevent excessive deviations of prices from competitive levels.

- To impose constraints on dominant companies,

- $\quad$ To support decisions on mergers and possibly to devise behavioral remedies.

- To guide market design choices.

- It is easiest to obtain information on market monitoring where a formal unit has been established. While the details vary from market to market, the 3 key activities of a market monitoring unit are to:

- Analyse the market on a continuous basis to identify potential problems that need more study, and to screen out undesirable behavior.

- Investigate any problems identified by its own screening, or by complaints from other stakeholders.

- Report on the results of its analysis and investigations on a regular basis. 
We will analyze the Indices and Models of detecting Market power. The techniques review includes structural and behavioural indices and analysis as well as various simulation approaches. The applications of these tools range from spot market mitigation and congestion management through to long-term market design assessment and merger decisions. Easily accessible and comprehensive data supports effective market power monitoring and facilitates market design evaluation. The discretion required for effective market monitoring is facilitated by institutional independence.

However, there is no universally accepted set of market monitoring statistics and indices. In practice there are a large set of data and indices that are monitored on varying time scales. The common themes: First, the level of market prices is perhaps the most obvious thing there is to monitor. However, a moderate market price can be a sign of market abuse if it comes at a time when demand is low. This means that prices must be related to system conditions; most importantly, the level of demand, but also the level of available capacity, and indicators of transmission congestion. Although not all these measurements are directly tied to a particular index of market power, they can sometimes indicate irregularities in the market that may be symptomatic of market power problems. Furthermore, such data may also facilitate the development of other standard metrics of market power. These statistics are typically reported on a monthly, seasonal, and an annual basis, but should be collected for every period in which the market is operating. A second set of indicators relate to the market structure, underlying features of the market that will change only gradually. This means that some of the data need only be collected periodically, rather than on a continuous basis. The raw data in this area consist of information on generator market shares and on the price responsiveness of demand. A third kind of analysis assesses the behavior of individual suppliers, which might have market power. In this area, the raw data consist of bid and outage information. The first transformation may be to produce reference bids, which indicate how each unit behaves in normal conditions. Further analysis can then focus on identifying the circumstances that might make such a change in behavior profitable, and checking whether the generator's behavior does indeed change in response. Similar analyses can relate unit outages to market conditions. The fourth type of analysis involves indicators of market performance. Liquidity measures are related to the number of suppliers in short term and long term markets and the volume of trade. The level of output that market participants have covered with long-term contracts is therefore crucial for the analysis of the incentive to exercise market power.

Some interpretation of data can be automated, but more complex patterns of exercise of market power can only be identified with more detailed and tailored analysis. Only an independent market monitor has the capability, incentive and market trust to allow it to detect the exercise of market power.

\section{Literature Review}

3-1 Terminology

Markets exist wherever buyers and sellers interact to buy or sell a product at a mutually agreed price. The Oxford dictionary of economics defines a market is defined "A place or institution in which buyers and sellers of a good or asset meet". However, the everyday sense of the word "market" also tends to include market participants, market conditions, legal framework, geographical area etc. Secondly, in practice, electricity markets comprise a sequence of overlapping markets (Stoft, 2002). Hence, a necessary step for the analysis is to define the meaning of the word "market" and other related terms with respect to their use in European electricity markets.

First, from the definition of the "market" are excluded generators, traders, distribution companies, and regulators, which can be played as "markets participants" while regulators, and laws and legal aspects constitute, the "market's legal framework". Second, since PX-s are markets for wholesale electricity, the retail market is excluded from the definition of a market. Hence, the word market will refer to all places or institutions in which buyers and sellers of wholesale electricity contracts meet to ratify. This includes both financial and physical contracts. Moreover these contracts can be traded on over-thecounter markets (hereafter OTC or bilateral contracts) and organized markets such as PX-s or power pools.

Market terminology (Oxford Dictionary definition in Italic);

Market: "A place or institution in which buyers and sellers of a good or asset meet". All places or institutions in which buyers and sellers of wholesale electricity contracts meet. The market includes all organized markets, i.e. PX-s, power pool, 
balancing markets and OTC markets, i.e. all type of bilateral transaction, where contracts for wholesale electricity are traded.

Marketplace or organized market: A third party, which facilitate the transaction between a seller and a buyer. Marketplaces have trading rules, which cover price setting, delivery, clearing, type of product, timing etc. For instance PX$s$ and power pools.

Bilateral markets or Over The Counter (OTC): "A market in securities not regulated by a stock exchange". Markets, which are not regulated by an organized market authority. These markets involve a direct transaction between a buyer and a seller.

Spot market: "A market for goods, securities, or currencies for immediate delivery or in some case a short time is allowed for delivery." These transactions can be realized through a marketplace and/or bilaterally.

$$
\text { Market }=\text { Wholesale } \text { market }=\text { Marketplace }+ \text { OTC }
$$

Power exchanges (PX-s) are one type of marketplace

\section{3-2 References models: perfect competition/monopoly}

The objective is to describe briefly the concepts of these two polar extreme models between which all other market models are ranged.

\section{3-2-1 Perfect competition}

According to the theory of perfect competition, and assuming a market for a homogeneous product with many buyers and sellers, the most efficient outcome is achieved if firms price at marginal cost. The model of perfect competition is based on four central assumptions.

- Atomicity: there are so many buyer and sellers that no single buyer and no single seller can affect the price.

- $\quad$ Product homogeneity: the product provided by the different competitors is exactly the same.

- Free entry/exit: any firm can enter or exit the market freely.

- Perfect information: all the players know the prices set by all the firms.

Each firm sets its price at the level of its marginal costs to maximize its profits. Hence, if a firm sets a price above the price of other firms it sells nothing. If a firm sets a price below the other firms', it will have to supply all of the market demand for the product. If a firm charges less than marginal costs, it will fail to break even for that unit of output. Results: in the perfect competition model marginal revenue equals price and each firm is price taker.

Figure 1: Perfect competition equilibrium

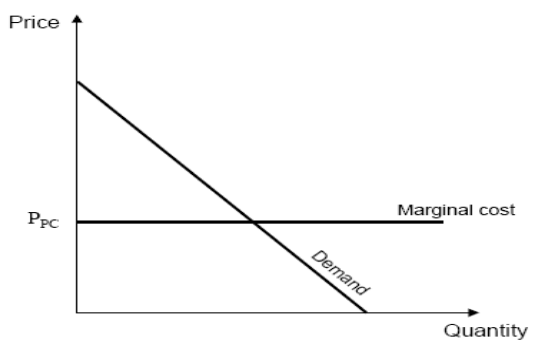

There are generally two types of equilibrium in perfect competition: short run and long run equilibrium. In the short run there is too little time for new firms to enter the industry while in the long run new firms can enter. 


\section{3-2-2 Monopoly}

The monopoly model assumes that there is one single firm, which supplies a well-defined market and that entry in the industry is blocked. The firm, called the monopolist, sets price $p$ or a quantity $q$ at a value that maximizes its profit. Since price and quantity are related to demand $\mathrm{D}(p)$ it is does not matter if the monopolist chooses the optimal price or the optimal quantity. The level of supra profit depends on the elasticity of demand. The monopolist is therefore price maker, figure 5 shows that the difference between the monopoly equilibrium price and the perfect competition price depends on the elasticity of demand, represented by the slope of the demand curve. When demand is inelastic the marginal revenue of selling an extra unit is low because a small increase in the quantity leads to a large drop in price.

Figure 2: Monopoly equilibrium
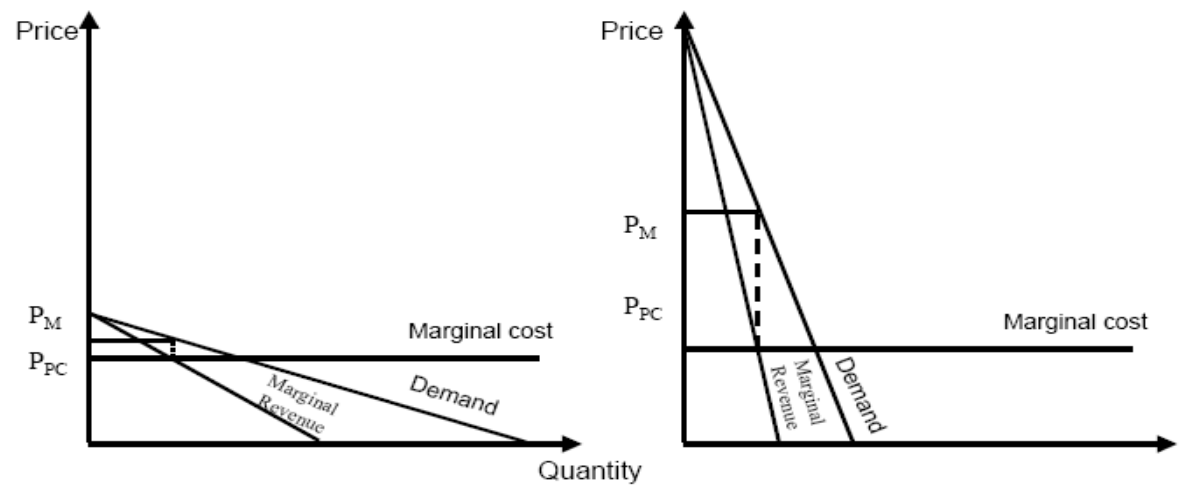

A monopolist can increase the price of a good by restricting its level of output. The ability to increase prices is limited by the elasticity of demand.

\section{3-3 Oligopoly competition}

Since both perfect competition and pure monopoly are extreme cases, rarely seen in practice, to analyze real markets, are developed alternatives models. The objective of these models is to cover the broad range of oligopolic competition between perfect competition and monopoly. Oligopoly competition refers to a market structure where a few players coexist. Each firm believes its profits are affected by the actions of others firms, and that these actions also influence the profits of other firms. Taking perfect competition and monopoly models as the end points, there is an infinite number of theoretical possibilities for oligopoly models, all of which differ mainly in the assumptions used to characterize market structure and firm interdependencies.

\section{3-3-1 The Cournot Model}

Cournot developed the first model of oligopoly competition in 1838 (Cournot, 1838), this model takes into account the interdependencies between firms. Cournot's assumption of is that each firm will choose a level of output with respect to the rival's production decisions. Thus, in such a model players compete on quantity. The basic model is a duopoly model $(n=2)$ where each firm has identical constant marginal production costs and faces linear demand.

Figure 3: Cournot equilibrium 


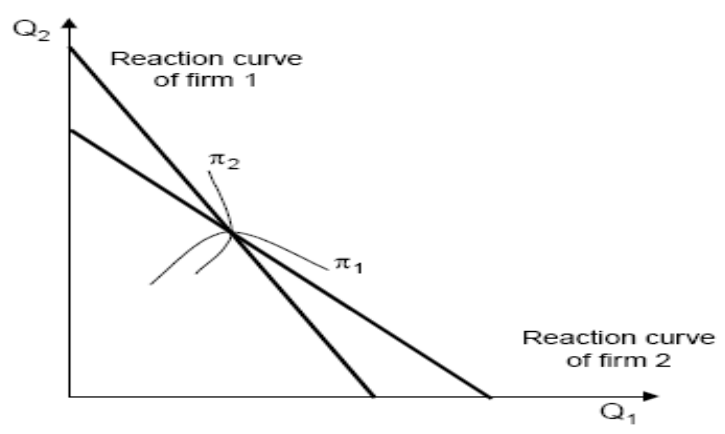

The two axes define the output of the firms, so that any point represents their respective production volumes. In this model the reaction curve represents how much each firm would produce given an output decision from the other firm. The intersection of the two curves defines the equilibrium where each firm has maximized profit, given the output of the other. This equilibrium is a Nash equilibrium (which is a situation where each player's predicted strategy must be that player's best response to the predicted strategies of the others players) since each firm is following its best course of action, given its expectations about its rival's actions and that the expectation are fulfilled.

Under the Cournot model the price depends of the level of output:

$P(Q)=a-b Q$

Where $P$ is the market price and $Q$ the total volume of output.

The total level of output is the sum of the production of each firm:

$\mathrm{Q} \quad=\quad \sum q_{n} \quad=q_{1}+q_{2}$

Where $q_{1}$ is the volume produced by firm 1 and $q_{2}$ the volume produced by firm 2

The profit of each firm $\mathrm{n}$ is defined by the difference between its revenues and total cost:

$$
\pi_{n}=P(Q) q_{n}-c q_{n}
$$

$$
\begin{aligned}
& \pi_{\mathrm{n}}=(\mathrm{a}-\mathrm{bQ}) q_{\mathrm{n}}-c q_{\mathrm{n}} \\
& \pi_{\mathrm{n}}=(\mathrm{a}-\mathrm{bQ}-\mathrm{c}) q_{\mathrm{n}}
\end{aligned}
$$

Where $\mathrm{c}$ is the unit cost.

In the Cournot model each firm assumes that the other will keep its level of production. Hence, firm $n$ maximizes its profit by differentiating $\pi \mathrm{n}$ with respect to $\mathrm{q}_{\mathrm{n}}$. The maximum level of output is found by calculating the first order conditions:

$\mathrm{d} \pi_{1} / \mathrm{dq}_{1}=0$

For firm 1 the maximum level output is then defined by:

$$
\begin{aligned}
& \mathrm{d} \pi_{1} / \mathrm{dq}_{1}=\mathrm{P}(\mathrm{Q})+(\mathrm{dP} / \mathrm{dQ}) \mathrm{q}_{1}-\mathrm{c}=0 \\
& \mathrm{~d} \pi_{1} / \mathrm{dq} 1=\mathrm{a}-2 \mathrm{bq}_{1}-\mathrm{bq} \mathrm{q}_{2}-\mathrm{c}
\end{aligned}
$$

Hence, the level of production of firm 1 is express using the level of production of firm 2 :

$\mathrm{q}_{1}=(\mathrm{a}-\mathrm{c}) / 2 \mathrm{~b}-0.5 \mathrm{q}_{2}$

This equation defines the reaction function of firm 1 to the level of output of firm 2 . Similarly the reaction function of firm 2 is:

$\mathrm{q}_{2}=(\mathrm{a}-\mathrm{c}) / 2 \mathrm{~b}-0.5 \mathrm{q}_{1}$ 
The equilibrium solution is defined by the intersection of the two curves

$q_{1}=(a-c) / 2 b-0.5\left[(a-c) / 2 b-0.5 q_{1}\right] \quad$ so $q_{1}=(a-c) / 3 b$

\section{3-3-2 The Bertrand Model}

Bertrand (1883) extended Cournot's model of by changing the rivalry notions using prices rather than quantity. In the simplest version of the model, two firms set their prices simultaneously. Since the two products are perfect substitutes the firm which sets the lower price will attract all the demand for the product in question. Again, we can use a reaction curve, only this time for prices rather than quantities. It is critical for the model that each firm has identical cost curves; otherwise the one which has lower marginal costs will always supply the entire demand. The Bertrand equilibrium is achieved when each firm's expectations about the price behavior of its rival are realized. The fundamental result of the Bertand's model is that industry has price and output level similar as under perfect competition. The reasoning is the following: when firm 1 has selected its price to maximize its profit, the best strategy for firm 2 is to undercut firm 1 by a small margin and take all the market. Hence, the best response of firm 1 is to undercut firm 2. This process ends when neither of the two firms can go any lower, i.e. when price equals marginal costs. For any price of a rival, a firm will opt for a price that is just lower. Equilibrium is obtained when price equals marginal costs.

\section{Albania energy market structure}

The approval of the Albanian Market Model is an important step towards the consolidation and steady development of the Albanian Electricity Market. This approval is part of the reform that the Government of Albania $(G \circ A)$ has undertaken for the reconstruction of the Electric Power sector, pursuant to the Law on the Power Sector and the policies of the Government for the development of this sector. Moreover, the AMM has been developed according to the EU Directives on Electricity and the requirements of Energy Community Treaty of South Eastern Europe for the creation of the Regional Market of Electrical Power, as ratified by the Parliament of Albanian in 2006.

\section{4.1 Participants of the Market}

The description of the Market Model set forth below outlines the responsibilities of, and relationships among, the market participants and the Energy Regulatory Entity ("ERE"). ERE has the responsibility for regulating performance by Market Participants of their regulated activities, under appropriate rules and regulations and in accordance with transparent procedures.

Law No. 9072 On Power Sector (effective August of 2003, and as amended) provides a legal basis for the exercise of those responsibilities by the ERE.

The Market Model also outlines the responsibilities of, and relationships among, the market participants and the Electricity Regulatory Entity (ERE). In broad terms, the Albanian Market Model is characterized by bilateral contracts for electricity between and among market participants. The Ancillary Services for the Transmission System are purchased by OST. The regulation of price and other terms and conditions under the Albanian Market Model is wide-ranging. It reflects the current near monopoly situation of KESH Gen, DSO, Wholesale Public Supplier, Retail Public Supplier and OST. All contracts and tariffs between the various market participants will be regulated at the inception of the market except for:

a. contracts between Traders, and Qualified Suppliers on one hand, and the Wholesale Public Supplier and Eligible customers, on the other;

b. contracts between SPPs and IPPs, on one hand, and Eligible Customers on the other;

c. contracts between KESH Gen, on one hand, and Qualified Suppliers and Traders on the other, to the extent permitted under the present or subject to other restrictions on KESH Gen sales; and

d. contracts between SPPs and IPPs, on one side, and Traders on the other.

Market Participants of the Albanian Market Model are as follows:
a. Transmission System Operator ("OST").
b. KESH Generation ("KESH Gen").
c. Small Power Producers ("SPPs"). 

d. Independent Power Producers ("IPPs).
e. External Suppliers.
f. Distribution Company ("Disco").
g. Tariff Customers.
h. Eligible Customers.
i. Independent Regulator ("ERE").

4-1-1 The Market Model's Essential Characteristics.

Shortly, the Market Model's Essential Characteristics and tools of Albanian Market are as follows:
a. $\quad$ Long Term Forecasting
b. Year Ahead Supply Contracts
c. Week Ahead
d. Day Ahead and In-Day Adjustments

Figure 4: Electricity Flow

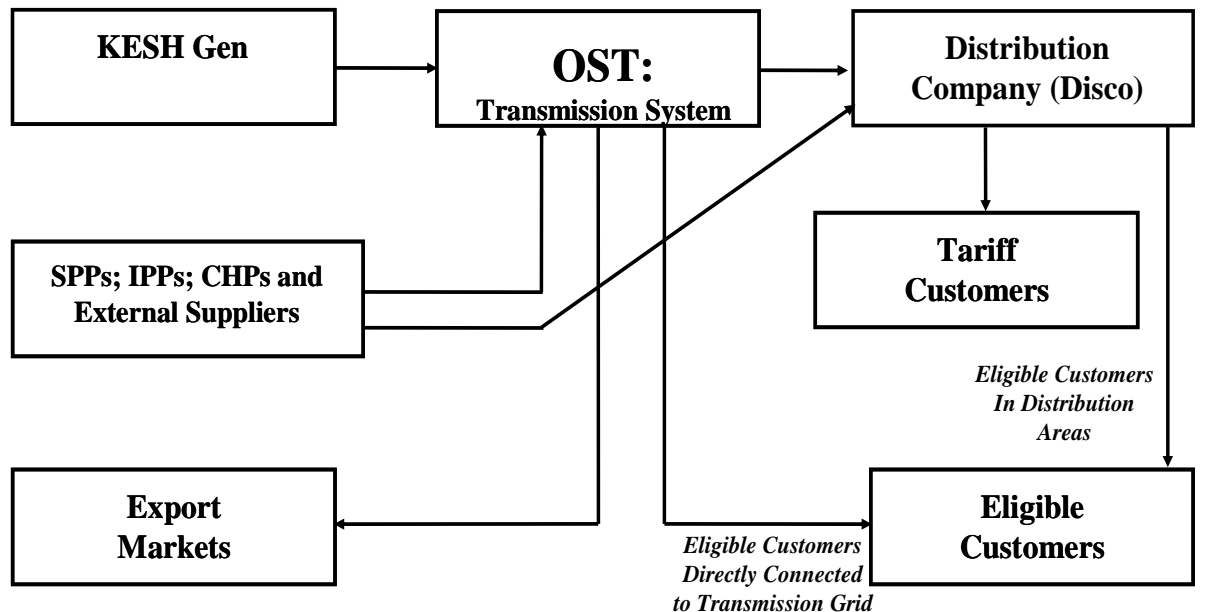

Figure 5 : Flow of funds

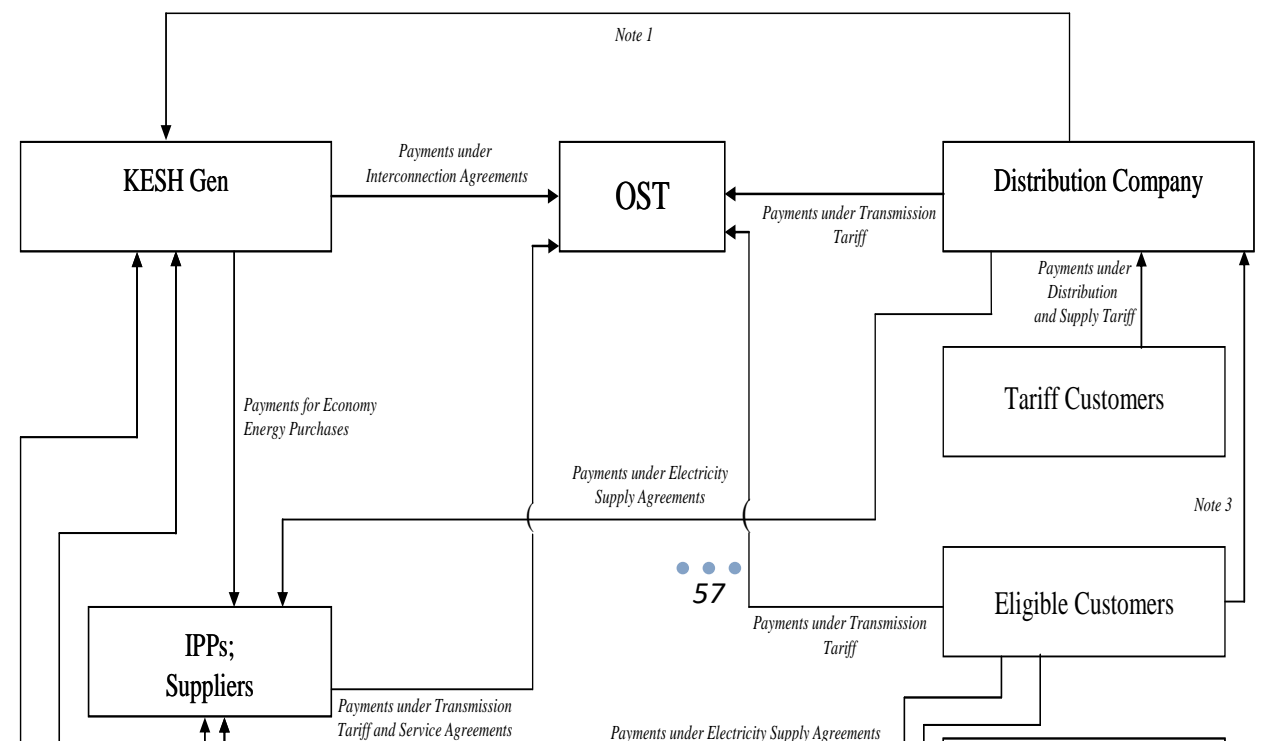




\section{The major conclusions from the analyses are:}

The Albanian Market Model need to take into consideration:

1. Provide a framework for privatization of the electricity sector, including the privatization of the distribution functions in the near term (i.e. by the end of 2007). The framework will provide a sound basis for privatization of further segments of the sector, such as generation, as conditions warrant;

2. Move toward consistency with EU Directives and the Energy Community Treaty;

3. Minimize opportunities for informal economic activity. The Market Model thus limits the role of the OST in economic transactions to improve transparency;

4. Capture the full value of the Albanian hydro resource for the benefit of Albanian tariff customers;

5. Enhance the financial viability of the sector by clarifying responsibilities and obligations and ensuring sufficient flows of information about the operation of the market and creating a clear structure for financial transactions;

6. Ensure that tariff customers have priority in the use of the transmission system; and

7. Provide Consumer Benefit.

8. Increasing of the institutional responsibilities + (cooperation between local and governmental institutions)

9. Legal framework harmonised with EU directives and strictly implementation;

10. Financing sources attracting; (EE and RES Funds)

11. ESCO-s to be introduced;

12. Energy Database improvement;

13. Awareness campaign increasing;

\section{Bibliography}

[1] Bunn, D.W., Modelling Prices in Competitive Electricity Markets (The Wiley Finace Series)

[2] Eydeland, A., Energy and Power Risk Management: New Developments in Modeling, pricing and Hedging

[3] Errera, S., Fundamentals of Trading Energy Futures and Options.

[4] Harris, C., Electricity Markets: Pricing, Structures and Economics

[5] Kirschen, D.S., Fundamentals of Power System Economics

[6] Lambert, J., Energy Companies and Market Reform.

[7] Pilipovic, D., Energy Risk: Valuing and Managing Energy Derivatives.

[8] Rothwell, G., Electricity Economics; Regulation and Deregulation (IEEE Press Series on Power Engineering)

[9] Sioshansi, F.P., Electricity Market reform: An International Perspective (Elsevier Global Energy Policy and Economics).

[10] Shively, B., Understanding Today's Electricity Business.

[11] Wengler, J., Managing Energy Risk: A Non-technical Guide to Markets and Trading 